This item was submitted to Loughborough's Research Repository by the author.

Items in Figshare are protected by copyright, with all rights reserved, unless otherwise indicated.

\title{
Expansive learning in contemporary construction organisations
}

PLEASE CITE THE PUBLISHED VERSION

https://doi.org/10.1108/BEPAM-06-2018-0092

PUBLISHER

(c) Emerald

VERSION

AM (Accepted Manuscript)

PUBLISHER STATEMENT

This work is made available according to the conditions of the Creative Commons Attribution-NonCommercialNoDerivatives 4.0 International (CC BY-NC-ND 4.0) licence. Full details of this licence are available at: https://creativecommons.org/licenses/by-nc-nd/4.0/

\section{LICENCE}

CC BY-NC-ND 4.0

\section{REPOSITORY RECORD}

Sackey, Enoch, Martin Morgan Tuuli, and Andrew Dainty. 2019. "Expansive Learning in Contemporary Construction Organisations". figshare. https://hdl.handle.net/2134/37412. 


\title{
Expansive learning in contemporary construction organisations: an exemplar in BIM-mediated projects
}

\author{
Enoch Sackey, Martin, M. Tuuli, \& Andy R.J. Dainty
}

Purpose - The evolving roles of BIM and smart building technologies in the design and management of construction projects often present unexpected events and variabilities, which tend to erode professionals' prior knowledge authority. The purpose of this paper is to explore how construction organisations can deploy knowledge and adapt to the requisite skills in order to make fitting responses to the ever evolving technological and organizational transformations to address the prevailing construction challenges.

Design/methodology/approach - The paper opted for abductive research approach which ensures back-and-forth iterative dialogue between the empirical data and an amalgam of the theoretical proposition towards new understanding of the phenomenon under investigation. Multiple case study method was adopted to collate the empirical data from three separate construction organisations as they transitioned into BIM compliant work processes.

Findings - The study has described new processes that not only mediate existing practices, but focuses on consistently resolving known tensions and contradictions between prior knowledge and the requirement of the changing work situation. The study also illustrates the cognitive synchronisation of the learning approaches within contemporary work organisations that align well with the merits and utilities entrenched within their niche technological choices.

Research limitations/implications - Due to the chosen research methodology, it is acknowledged that future comparative studies using a much larger quantitative data sample to further elucidate the findings of this paper would be an interesting further step.

Originality/value - The study contributes to construction management literature by providing new insights into expansive learning environments capable of addressing cognitive contradictions and ambiguities inherent in the changing contemporary work patterns in the construction context as a consequence of BIM deployment.

Keywords: BIM, construction technologies, expansive learning, knowledge development, case studies, contemporary organizations

Paper type: Research paper

\section{Introduction}

There is a widespread consensus in the extant literature regarding the positive effects of utilizing innovative construction technologies to address some of the prevailing challenges in construction (Hartmann et al., 2012). Buildings, infrastructures, material choices and design decisions greatly impact important areas of society, such as quality of life, energy consumption, waste generation, and pollutions (Ortiz et al 2009). The deployment of the emerging BIM technological artefacts to leverage optimal design solutions for the prevailing construction challenges therefore has high societal value. Existing cutting-edge technologies have made it possible for building components to be objectified within BIM models with parametrically-embedded properties and relationships amongst the objects (Sackey et al., 2014). The BIM concept describes the process of using available technological artefacts to produce data-rich, object-oriented and parametric representation of a facility on a digital platform which enables the various construction stakeholders to effectively use add reuse the model to coordinate, design, construct and operate a facility (e.g., Sackey 2014). The current possibilities with BIM technologies include the ability to provide cloud-based virtual platforms for project metadata management (e.g., virtual sharing, using, updating and archiving project information) including tools for quantity takeoffs, scheduling, and resolution of variances in coordinated models, energy analysis and usage, and immersive remote 
observation of project sites. BIM-mediated projects refer to projects in which BIM is appropriated. The concept of appropriation is intended to account for the specific ways by which BIM platforms are incorporated and institutionalised within the organisational settings.

Indeed, the recognition that technological solutions are strategically important to construction organisations is incontestable (Hosseini et al., 2013). Nevertheless, this comes with a responsibility to increase organisational capacity to cope with the drastic shift in paradigm regarding organisational reconfiguration. For instance, the implementation of BIM and other construction technology enablers requires a redefinition of some professional roles, responsibilities and relationships among actors involved in a project (Sackey 2014, Linderoth, 2010), or among professionals working in multidisciplinary organisations (Steel et al., 2012).

Thus, the implementation of all-encompassing BIM for optimum interoperability and synchronous communication is still an aspiration of the construction industry in general, but not an achievement. This is mainly because, BIM deployment requires reeducation, training, and rethinking of certain entrenched construction practices. Indeed, BIM deployment within construction organizations does not just invoke change of technology, but the change of task, structure and personnel. There is a wholesale change in technology through, for instance, the move to central repository platforms for federated data interchange among the heterogeneous professionals (Sackey et al., 2014). There is also a wholesale change in structure that supervene the existing functional requirements and roles of the workforce. This calls for an equally compensatory learning and support structures for the workforce within the organizations.

Notably, the concept of BIM, its implementation strategies, and associated benefits to the construction sector have widely been articulated in the academic literature (e.g., Eastman et al., 2011) but, the related changes in learning and competence development for the industry's eclectic professional workforce has rarely been analysed empirically at the level of mundane work activities. The study attempts to close this knowledge gap by carrying out empirical studies of related learning and competence development within BIM-enhanced construction organizations as they pursue and transform their business ambitions and activities via the rollout of novel construction technologies.

The study examines the expansive learning activities of construction professionals within the workplace. Specifically the paper explores the facilitative learning strategies in adaptive ways to make fitting responses to the technological and organizational transformations. The paper begins with a discussion on the challenges of the conformist learning trajectory in contemporary organisations, followed by a review of the expansive learning construct, focusing on its applicability within contemporary construction context. The next section describes the design of the study, including the case study data collection strategy, the research participants and the contexts of the study. The results of the findings are then presented and discussed. The study concludes with the summary of the main findings and their implications to practice.

\section{The modus operandi and learning trajectory in the contemporary work context}

Higher Education Institutions (HEIs) with the requisite academic resources have been the major source of supply of knowledge workforce to the construction sector (BecerikGerber, et al., 2011). The conventional approach to knowledge development within 
HEIs is mainly embedded in transmitting established knowledge to augment or develop existing practices (Zeichner et al., 2015), and has proved to be an effective mechanism for preparing workers for roles that evolve slowly over time (Milligan et al., 2015; Underwood \& Ayoade 2015). This bought-in approach to knowledge development lacks flexibility as it relies on prior knowledge to mediate and counter the disruptive events and variabilities of the new technological artefacts, and it is also constrained in terms of time, space and content. Thus, it does not offer sufficient solutions to the challenges of the contemporary construction organizations, where the evolution of technologymediated work is very rapid. The contemporary construction workforce does not only operate in existing knowledge culture, but the work practices are constantly being facilitated by new and emerging technological artefacts which calls for new knowledge cultures. Hence, beyond the higher degrees and formal qualifications is the need for an established, context specific, socially embedded learning environment, which is not constrained by time, content and space. There is therefore a sharp contrast between the conformist educational culture and the learning requirement of the dynamic contemporary work setting.

The ascending role of the BIM vendor market in regulating the professional work through the application of the ever evolving authoring tools in the design, engineering and management of project works often erodes professionals' prior knowledge authority (e.g., Sackey et al., 2014). Indeed, different researchers have analyzed the various impacts of technological transformation in construction organizations, resulting in the emergence of new professional fields or the hybrid of existing job requirements. Sackey et al. (2014) for instance, presented how construction organizations are transformed and the creation of new roles as a consequence of BIM technological rollout in construction organizations. These new job requirements seem to expand existing professional knowledge boundaries. Lehtinen (2012) recognize that change in professional workforce' attitudes and skills often accompany new technological and organizational development within the workplace. It is therefore vital that construction organizations are able to effectively tailor their processes and the knowledge workforce to align with the technological artefacts to harness the new functionalities of the technologies whilst countering any uncertainties and disruptions that accompany the change process.

This study therefore aims to unravel a better understanding of learning models that appropriately respond to the rapid trend of technological shift in the construction work context. The activity theory and its reference to expansive learning lexicon (Engestrom 1994) appear to offer a platform for knowledge development at the edges of new competences, innovations, and uncertainties to leverage impending technological possibilities. According to Engestrom (1994), expansive learning starts by criticizing, questioning, and analyzing existing practice, thus the theory focuses on consistently resolving known tensions, contradictions and conflicts within the work system.

\section{The expansive learning concept and its bearing on the contemporary work system}

The construction industry is well-known for its greater emphasis on project and performance outcomes at the expense of innovation uptake and human resource development (Raiden et al., 2006). Given what is known about the context of the contemporary construction sector, and the need to actively pursue new knowledge, expansive learning is proposed as conceptual framework to guide understanding of knowledge development, particularly in relation to technological transitions. The 
expansive learning construct relates to opportunities for learning by introducing tools or approaches that seek to highlight the disparities between the learners' current knowledge and new learning objectives (Anthony, Hunter, \& Thompson 2014).

Engestrom's $(1994 ; 2001)$ activity theory and its reference to expansive learning lexicon offer a perspective for viewing changing organizational learning within the context of developing activity. An activity system is constantly working through contradictions between its elements. The contradictions typically emerge through the historical process of transforming established patterns into new mode of production. These tensions within the work system activities are understood as a driving force for expansive learning; that is, resolving current contradictions by developing new form of activity based on an expanded understanding of the object of the activity (Engestrom 2001). The case of BIM technological deployment is an illustrative example of learning challenges emerging in the subsequent stage of expansive transformation of construction innovation.

The theory has widely been referenced in organisational learning research and has been applied to a variety of studies to understand adaptive work-based and professional learning (e.g. Yeyinmen 2016). The theory underscores the development of the knowledge workforce to align with the immediate demand of the environment, whilst acting with a conscious understanding of how facilitating artefacts would be broadly relevant to time and space (Yeyinmen 2016). This reality is enabled by perception that is oriented to the need of the present and the recognition of the facilitating supports that leverage continuous learning by the knowledge workforce within their immediate work system.

The key value of contemporary organisations lies in the knowledge of its workforce. Denis et al (2013) averred that dynamic organizations can exhibit expansive (facilitative) as well as restrictive (disabling) elements to learning. The likelihood that learning would take place in any context is dependent on the learning opportunities afforded by the organization to the individual and how the individual perceive this opportunity in relation to their role (Milligan et al 2015). Contemporary work organizations are often presented with unexpected events and variabilities. Consequently, the expansive learning notion facilitates an environment where the knowledge workforce is able to reflect on the prevailing contradictions, and coevolve with the growing network of epistemic artefacts to expand the edges of competence in order to resolve unforeseen or atypical situations within the work context. Such conceptualization helps the knowledge workforce to effectually respond to change by reconsidering their current practice or prior knowledge in relation to emerging capabilities and related processes.

Expansive learning theory is explored in this study as a necessary step to better understand knowledge development and changing processes in the knowledgeworkforce. From this theoretical perspective, embedded technological infrastructures and applicable software usage are understood as evolving, and are envisioned to encompass transformative organizational learning process involving the knowledge workforce across the interdisciplinary boundaries of the profession. This introduces a continuous process of learning to rethink the use of existing tools and processes.

\section{Research Approach}

This study investigates organizational strategies for learning and knowledge deployment in BIM-enhanced construction organizations via the lens of expansive learning theory. 
In line with the research agenda, the term "abduction" captures well the research approach taken in this study, i.e. a close "back-and-forth" interaction between empirical data and theory (Dubois \& Gadde, 2002). Hence, the research approach is based on learning from experiences and patterns exhibited by practitioners in their environments, and informed by a broad interest in construction organisational expansive knowledge development strategies during a period of technological transformation (Goddard \& Melville, 2004). Typical of an abductive research is that the empirical observation evolves simultaneously and iteratively with the proposed theoretical framework towards a new understanding of the phenomenon under investigation. The abduction method is appropriate for this study because it allows for iterative dialogue between the available empirical evidence and the proposed theory so that the two can evolve simultaneously to generate new insights regarding the phenomenon under investigation, and in this context, the appropriation of the organisational knowledge to align with the ever evolving BIM concept. The main unit of analysis and the subunits for the study include the selected organisations and their boundary practices as they focus on the salient aspects of BIM deployment. This includes individuals and their experiences and perceptions of the organisations' facilitative learning strategies to augment the BIM deployment processes.

Qualitative data is predominantly used in abductive research work to explore the socially constructed nature of reality and the situational constraints of the enquiry (Goering \& Streiner, 2013; Strauss \& Corbin, 1998). Yin (2013) presented four kinds of case study designs, distinguished by the number of cases and the number of units of analysis in each case. Single case designs are usually deployed to test a well formulated theory, whilst multiple case designs are deployed when two or more cases are required to serve a specific purpose within the overall scope of the enquiry. Multiple case study design can therefore comprise a single unit of analysis (holistic) or multiple units of analysis (embedded). The latter scenario was considered a better fit for this study which proposed to explore contemporary learning strategies in BIM-enhanced construction organisations. Multiple cases are chosen to literally or theoretically replicate other cases, or extend emergent theory, or to fill theoretical categories and provide polar examples. The evidence gathered from multiple cases is often considered more persuasive, and the overall study is thus regarded as more robust (Yin 2003). In order to achieve this, Yin (2003) posits that each case must be carefully selected to obtain either a literal replication (similar conditions/criteria are used to guide the selection of cases in order to predict similar results) or a theoretical replication (predicable contrasting criteria). Following the literal replication logic, it was decided to stratify the selection of the case organisations based on two main similar characteristics; 1 , their nature of work - construction-related organisations, and 2, demonstrable evidence that the organisations are in the process of (or has already) deployed BIM as part of their work processes. The findings, therefore, could help generate a refined theoretical abstraction through analytic generalisation (as opposed to universal generalisation). It draws implications from specific domain (e.g., the case organisations) which may help in understanding parallel phenomenon in other similar organisations or contexts.

Per the recommendations of Butterfield et al., (2005), credibility and trustworthiness measures were taken to promote confidence in the findings and conclusions of the study, comprising; triangulation in the data collection across the three cases; descriptive validity (working with transcribed interviews for accuracy); interview fidelity (probing as much as possible to discover the different perspectives of the interviewees); and; theoretical validity (demonstrating how the emergent themes from 
the study are consistent or inconsistent with previous research). The data collection strategy also conforms to standard of rigor by relying on three embedded case studies of BIM-enabled construction organisations (e.g., Kaplan \& Orlikowski, 2013).

The data collection involved: documentation of organizational and project activities, observing formal organizational meetings, conducting 26 formal interviews across the organizational hierarchies, collecting relevant documents for each case organization, and participating in frequent informal communications (e.g., email exchanges and telephone discussion). All the 26 personnel interviewed had varying, yet relevant professional backgrounds, and years of experience ranging between 2 to 30 years. Over $40 \%$ of the participants have 10years or more working experience in their respective professional fields. Some of them were heads of their departments, and managers in various capacities. Considering their backgrounds and experiences, all the responses from the interviewees are considered valuable in portraying a clear picture of the company's BIM strategies and in providing answers to the objectives this case study sets out to achieve. The use of various data collection methods helps to establish triangulation and reveal contradictions and agreements in the reporting of events.

\subsection{Data analysis}

Bogdan \& Biklen (1997) noted that data analysis must involve working with, organising, and breaking data into manageable units. The process of coding, or identifying categories, and themes is useful in organising and managing the data derived from the case organisations. The analytical process for this study was very iterative involving coding that depicts the development of chronologies of the ongoing organizational transformation and the emergent strategies to cope with the change, and frequent reference to existing literature and the proposed theory as different themes emerged. Axial coding procedure (Strauss and Corbin 1998) was used to piece together the connections between different categories of the transcribed data. From the primary data sources, all key phrases in their immediate context that directly respond to the subject matter under investigation were coded into a spreadsheet. The outcome was a collection of coded segments gathering together all instances of data referring to that code. Saturation was achieved when no new code appeared. These codes were drawn together and disaggregated into relevant categories through axial coding in iteration with the extant literature. This helped with pattern recognition in the raw data, and themes becoming the categories for analysis and further discussion (e.g., Bowen 2009). The coding aided in making comparisons and connections between and among the identified themes and in iteration with the extant literature and the described theoretical position of the paper.

\section{Profiles of the selected case organisations}

The case study approach stresses the socially constructed nature of reality, and this study has explorative connotations in order to unravel the learning models that appropriately respond to the rapid trend of technological shift within the selected case organisations. The exploratory case study is a valuable means of formulating problems more precisely, to seek phenomenon in new light and to form hypotheses (Yin 1989). It also has a considerable ability to generate answers to the questions 'why', as well as 'how', hence the essence of adopting this approach. Amongst the criteria for the selection of the three case organisations include demonstrable evidence of in-house BIM implementation strategy and with ongoing or completed BIM projects. The profile 
of the three case studies, henceforth, CS-Alpha, CS-Beta and CS-Gamma are presented in this section. CS-Alpha operates successfully in a large construction organisation and is featured in the top-20 UK contractors' list, CS-Beta is a large construction product manufacturer and inherently aims to maintain a competitive position in the zero-carbon construction products market and CS-Gamma is a small firm that provides consultancy and technical services in structural detailing and architectural metal works.

The section that follows presents an analytical overview of learning and knowledge deployment strategies to augment BIM best practices within each of the selected case organisations.

\subsection{Analysis of BIM deployment within the case organisations}

\subsubsection{Organisational overview and strategies for leveraging BIM within CS- Alpha}

CS-Alpha has consolidated its performance structure into three main market sectors, comprising: construction, housing, and maintenance, and is widely recognised among the largest privately owned construction companies in the UK. Within CS-Alpha, BIM technologies were seen as innovative solutions to improving construction project delivery while at the same time allowing the organization to eliminate unnecessary waste and to offer cost savings to clients. Clients demand, and the new functionalities were cited as significant drivers for implementing BIM in the organisation. Amidst an industry-wide campaign towards BIM utilization on projects, CS-Alpha has been prompted to adjust the organizational workflow to suit the demands of its clients and the trending market conditions. In this regard, it is possible to see how BIM technologies were shaping the operations of CS-Alpha and simultaneously reshaping the activities of the operational team involved in delivering featured BIM projects. There were also some concerns, about how wide-scale BIM capability and workflow across the entire offices of CS-Alpha is likely to undermine the firmly-established institutional structures of the organisation.

Recognizing that BIM deployment is a catalyst for corporate business process change, a BIM implementation strategy team was formed in CS-Alpha to provide a direction and a strategy to govern the implementation process. The team consists of a whole mix of membership across different hierarchies within the business and headed by a BIM manager who has been in the organization for circa nine years as the head of design management - managing preconstruction design processes, until taking on his new role. The team was tasked inter alia, to: ensure a gradual and continuous BIM implementation until it becomes the standard of project delivery across the wider business; provide organization-wide support on how to utilize new and emerging BIM product suites to provide efficiencies in the process of BIM project delivery, and; to develop BIM implementation protocol that can be followed to successfully deliver BIM projects throughout the business on a national scale.

Although the central corporate BIM team was established to develop and roll out an organization-specific standard BIM methodology across the business, CS-Alpha also solicited the services of external expertise to augment the capability of the internal team. The external support was derived from a consultancy firm that has expertise in IT systems supply and implementation, training and support in BIM and other related construction IT solutions in design, construction and assets management. The external team was tasked to provide technical assistance in the selection and installation of new 
software and hardware to fulfil CS-Alpha's BIM requirements. The external expert team was well-positioned to configure the organisation's hardware and software having first-hand knowledge of the organisation's requirements from the outset. Overall, the external consultant helped to fine-tune the corporate BIM team's understanding of the significant changes BIM required from a traditional 2D construction environment. By extension, such knowledge was shared across the broader workforce of the organization.

It was noted that, having a team of external experts and dedicated internal corporate BIM team to develop the organisation's BIM strategy, was not necessarily sufficient to invoke change at the operational level. Both the centralised BIM experts and the local project teams needed to work together to develop a clearly prioritised work plan to implement the BIM vision throughout the business operations. The central corporate BIM team was widely considered in CS-Alpha as the in-house BIM resource that provides technical support and systemic training for staff development across the business - particularly focusing on the specific BIM skills of the operational staff such as 3D knowledge of BIM, component-based design and analysis, or providing experience with the use of BIM software.

Of a particular significant to the BIM knowledge development strategy within CS-Alpha was the active participation of "local BIM champions" in the BIM support structure. These trained "technology-savvy" individuals provide a strong boost to those at the operational level that struggle to cope with the change uncertainties, complexity of or concerns related to software use, hardware issues, and difficulties related to process change. A BIM manager emphasised that: “...BIM champions and users are identified within our local company offices to drive its implementation and raise knowledge at a local level.... They are the ones, where it is almost like a hobby wanting to use the latest technology. What you are trying to achieve is to take their passion and enthusiasm, add the technology to it, and get some organization standard, to form - this is the way that we actually want to work." From the above narrative, it is clear that the local BIM champions are identified within the local offices, trained, and empowered, and strategically placed at the operational level to help counter any BIM implementation resistance or any concerns raised by the local workforce pertaining to the organization's BIM agendas.

\subsubsection{Organisational overview and strategies for leveraging BIM within CS-Beta}

CS-Beta has secured a unique niche in the design, manufacture and construction of environmentally friendly building components and has specialised in building lowcarbon infrastructure projects from power plants, roads and bridges to housing, schools and hospitals. In order to sustain its sustainability agenda in the provision of low energy building solutions for its clients, CS-Beta recognizes the need to continually engage with innovative construction technologies. Accordingly, the company has committed internal resources to, and emphasis has been placed on, nurturing a continuous flow of new and cutting edge construction technologies as enablers in the most highly efficient design, manufacture and installation possible. BIM is perceived to play a central part in helping meet the company's strategic goals. This was emphasized by a Technical manager when he stated that: "here at [CS-Beta], the application of BIM is a key driver behind our philosophy to provide the best service for our clients". However, upon creating the necessary smartBIM objects with the company's products, it became clear that the products innovation was stimulating revolutionary changes in most aspects of the organisation's processes, which were contrary to the inherent status quo - hence, 
calling for a need to instigate staff training, human resource management and external relations.

The evolving technologies that augment the BIM processes came with some steep learning impediments. One of the biggest changes was behavioral change in employees' learning habits. According to a technical manager, one-off training is not enough because the BIM tools are continuously being improved, thus the company ensures that the skill-set available is continuously assessed and work is put in towards maintaining consistent knowledge across time. Technical competencies, work processes, and BIM tools which the workforce are to use in order to engender BIM implementation success are well documented in the design and engineering department of the case organization. This information is used to develop roles and requirements. Accordingly, this has helped the company to ensure that its employees are given relevant training and are fully involved in helping deliver the company's sustainability agenda with the use of latest technologies.

The organisation's BIM platforms are oriented to the specific workflows of each department. The authoring tools serve purposes such as modelling, producing drawings, energy analysis, coordination, fabrication, and generating specifications and quantity take-off for costing and/or scheduling from the developed model on a digital platform. In order to utilise the different functions of the BIM platforms for the benefit of the company, CS-Beta established relationships with its preferred external BIM vendor to help incorporate BIM technical competences and technological artefacts to suit individual needs of the various internal functional departments. CS-Beta also initiated an 'accreditation appraisal scheme' that guarantees that any new system upgrade from its vendor would be recompensed with staff competency training so that staff would be consistently up to-date with the use of their selected BIM platforms. The external support services are leveraged by an in-house technical team. The technical (design and engineering) department of the organization is mandated to facilitate the growth of BIM expertise and to manage the associated best practices in the company.

The technological change also prompted a new approach to Human Resource Management (HRM) within CS-Beta. The head of the engineering department believes that due to demand-supply deficit of BIM experts there are currently personnel "poaching" going on among competing firms. This calls for CS-Beta's HRM team to assist in developing a comprehensive employee retention strategy. One of the challenges the company did face, initially, was a disconnect between the HR practices and the human resource needs of the different departments - to the extent that a technical manager described the HRM approach to personnel management as creating some "other cocktail of values" irrelevant to the present training needs of the workforce. This unaligned HR strategy required that the company review its HR policy with respect to BIM. Clearly, in order to properly develop BIM proficiency and employee retention, especially the best, well trained and experienced ones, Human Resource (HR) actions are preeminent. Moving forward, one noteworthy strategy in CS-Beta was to ensure that the HR department was fully involved in the decision to develop and sustain a BIM competent workforce. The HR team liaised with each of the departments in creating high-level business goals with respect to improving knowledge development and increasing staff retention via performance-based competitive rewards and training opportunities. The HR department also became the pivot through which skill development and new recruits are organized within the company. Thus, managing BIM training programs, leadership development, and performance assessment criteria of all staff across each department became an extended responsibility of the HR department. 
The HR therefore helped in the BIM knowledge development process within the company by managing individual progression through different managerial levels, and sustaining employee retention through performance-based rewards and competitive salary structures.

\subsubsection{Organisational overview and strategies for leveraging BIM within CS- Gamma}

CS-Gamma original business model related to the design and construction of structural steel works. Upon investing in BIM design solutions, CS-Gamma rebranded itself as a multidisciplinary practice, providing not only structural design solutions but also other construction design and prefabrication solutions. These encompass, design, consultancy, creation of structural models, and production of fabrication module information and NC (numerically controlled) data to allow accurate manufacture and installation of a variety of projects from structural steelwork to architectural metalwork and staircases. The company is committed in utilising the latest available supporting technologies to complement its expertise and experiences of the workforce to meet clients' expectations, and ultimately, to warrant repeat business.

Prior to adopting the appropriate BIM platform for its business operations, CSGamma embarked on a comparative analysis until it recognised Tekla to be a useful tool for producing complex bespoke models for steel work design. A manager opined that, they find Tekla products to be "quite intuitive" and it gave "reasonable flexibility for structural detailing and accurate prefabrication information" via NC data production. The product also has a "shorter learning curve" - which was a selling-point to the business. CS-Gamma and Tekla signed a flexible licensing agreement to enable the use of Tekla BIM related products for the execution of BIM-enhanced work activities within the organisation. The agreement covers technical and maintenance support, and access to the latest versions of Tekla products. This ensures that, the operational team could access the products best suited to their workflow, from a portfolio of Tekla software tools which are useful for structural design, modelling, viewing, coordination and information sharing. These digital products include, Tekla structure, Web Viewer and BIMsight. The managing director asserted that they had chosen this licensing model from Tekla (regarding the products and services package) as part of a corporate strategy to ensure the organisation is able to effectively support clients' needs. Vendor supports and systems maintenance are part of the license agreement the organization and its preferred BIM solution providers negotiated on as indicated in this narrative: "The added value of the licensing agreement is that consultancy and training included, this ensures that our staff have the competencies to deliver quality services. To complement this, we attend annual trainings and presentations on the latest products. We also get all the documentations towards what new features there are and train our staff on them." The above statement indicates that the company relies more on its BIM solution providers to support its workforce with their required training needs, especially with the launch of any new product version.

The director of CS-Gamma acknowledged that the extent to which the BIM vision is realised depends on the employees' skills and attitudes as it is on leadership and management support. But also bemoaned that very often, the employees that join the company do not have the specific skills the business requires. This could perhaps, be attributed to the lack of industry relevant BIM training courses in the conventional academic institutions. 
To address this challenge, the organization developed internal training and management structure to support employees across the ranks - from apprenticeship, through engineering to senior-level positions. According to the managing director, there are ample opportunities for employees to climb up the hierarchy within the company as it aims to "train, develop and mentor the future structural engineers and detailers of the business by offering them vocational training and hands-on-experience." A notable support structure for the apprentices is that, CS-Gamma established a partnership with a local college where the apprentices receive some of their trainings. After attaining the necessary qualifications, the employees are then assigned to a project with a skilled engineer as a mentor. The training structure sets the foundation for young starters to work their way up from apprenticeship level through to senior management level. The organizational support structure and the available opportunities also meant that employees are expected to often learn new skills and take more responsibility. This it is considered to be a significant employees' development initiative for a small firm like CS-Gamma.

\section{Discussions: emerging themes on facilitative learning approaches for BIM- compliant project delivery}

The three case organisations studied, subscribed and appropriated the use of different BIM platforms applicable to their specific needs and organisational objectives. Within the case organisations, expansive learning approaches that facilitated the knowledge practitioners' adaptation to work configurations in recognition of the emerging technologies were witnessed. Particularly, the organisations worked closely with external institutions and technology vendors who acted as boundary spanners to integrate technological capabilities into the internal work processes. In other instances, technology-savvy local "BIM champions" were nurtured and developed into becoming the conduit through which the BIM knowledge processes disperse into the mundane work routines. One organisation also engaged with local academic institution to train the operatives to acquire their formal qualifications, whist concurrently shadowing a mentor on the work front. Thus, from the findings of the case organisations, four main themes of facilitative approaches to augment expansive learning emerge, comprising: 1 . Partnership with educational institution for apprenticeship support and qualification; 2. Development of technology-savvy local BIM champions; 3. HR-driven incentivisation and retention strategy of the knowledge workforce; and, 4. Engagement with external BIM experts and technology vendors for technical support. Table-1 links the emerging themes with the respective case organisations and are further discussed with supporting literature in the section that follows.

\begin{tabular}{|c|c|c|c|}
\hline $\begin{array}{l}\text { Case } \\
\text { Organisations }\end{array}$ & CS-Alpha & CS-Beta & CS-Gamma \\
\hline $\begin{array}{l}\text { Themes for } \\
\text { expansive } \\
\text { learning and } \\
\text { knowledge } \\
\text { development } \\
\text { across the } \\
\text { case } \\
\text { organisations }\end{array}$ & $\begin{array}{l}\text { - Corporate in- } \\
\text { house support } \\
\text { team } \\
\text { - External } \\
\text { technical } \\
\text { support } \\
\text { - Technology- } \\
\text { savvy local } \\
\text { BIM }\end{array}$ & $\begin{array}{l}\text { - In-house technical } \\
\text { team } \\
\text { - } \text { External technical } \\
\text { support } \\
\text { - HRM support strategy } \\
\text { and reward } \\
\text { commensurate to } \\
\text { performance r hosting } \\
\text { - Web-based r }\end{array}$ & $\begin{array}{l}\text { - In-house BIM management } \\
\text { strategy } \\
\text { - } \text { Flexible licence agreement } \\
\text { with BIM products' vendors } \\
\text { - } \text { Tailored apprenticeship } \\
\text { training and qualification via } \\
\text { partnership with local college } \\
\text { - Knowledge development } \\
\text { strategy - from apprentice to }\end{array}$ \\
\hline
\end{tabular}




\begin{tabular}{l|lll}
\hline & champions & $\begin{array}{l}\text { support of proprietary } \\
\text { BIM objects }\end{array}$ & senior management (figure-1) \\
\hline
\end{tabular}

Table 1. Expansive learning and knowledge development themes for leveraging BIM across the case organisations

\subsection{Partnership with educational institutions for apprenticeship supports and qualifications}

It has been argued that, the professional skills required for performing technology related functions within the Architecture, Engineering and Construction (AEC) sector is beyond the scope of what is traditionally offered by academic institutions (Lee \& Hollar, 2013). Although academic institutions are recognised for being meticulous and thorough in their approaches to cascading new knowledge though teaching and learning, they are also known for being generally slow and introverted when it comes to developing a new programme or updating an existing subject-matter (Lee \& Hollar, 2013).

Notable strategies observed within the case organisations in facilitating new knowledge development between industry and academia included the BIM vendor products licensing training agreement, and more particularly, the established partnership with local college to supplement apprenticeship training development in CS-Gamma. The intransient collaborative effort, as observed between CS-Gamma and a local academic institution is considered to be quite significant, because it tends to align the academic syllabi and certification programmes with the organisation's corporate strategy of developing BIM competence of the apprentices through the formal qualification channel. The formal apprenticeship training efforts were supported in-house, through the hands-on mentorship scheme afforded to the apprentices to shadow a senior engineer on ongoing BIM projects, thus ensuring skills sharing and knowledge transfers of the BIM concept amongst the ranks of the operational staff. Also worth stressing observations within the case organisations was the flexible licensing agreement with the preferred BIM vendors, which mandated the vendors to offer technical support, training and access to a wide range of BIM authoring tools to the workforce.

While the study acknowledges that there are some academic institutions that have developed syllabi on augmenting BIM technologies to the next generation workforce, there is also a recognition in the extant literature that widespread BIM education that comprehensively links industry requirements and academic programmes is still in the early stages (Kinnane \& West, 2013; MacDonald 2012). Also, current BIM programmes offered in the UK educational institutions for instance, appear to mainly focus on the most rudimentary understanding needed for the industry, which is not sufficient for the knowledge expectations of the contemporary work front (BecerikGerber, et al., 2011). The disruptive nature of emerging technologies embroiled within the existing contemporary work routines, coupled with the preservationist role of the mainstream educational system could impede on expanding the frontiers of the technological possibilities with the requisite knowledge to effectuate better practices within construction. Hence, a mutual industry-academic collaborative effort, which is amenable to technological fluidity as demonstrated within the case organisations, could be a useful solution and a good strategy in addressing the consequence of the rapid pace of technological change within the AEC sector. This is important, especially as BIM is seen to help decipher the highly fragmented processes in the AEC practice (Anumba et al., 2002). 


\subsection{Development of technology-savvy local BIM champions}

Another way of pursing a facilitative learning to expand the boundaries of technological novelty within the case organisations was through technology-savvy gatekeepers at the operational level. The analysis in CS-Alpha, and indeed, in CSGamma showed the keenness of these two organisations on developing technologysavvy BIM champions to drive the implementation process from the bottom-up. These referred BIM champions are identified as the ones who are embedded in technologies and with a strong enthusiasm of "wanting to use the latest technological tools". These technology-aware and committed individuals make an important contribution in bolstering organisation's BIM implementation efforts from downstream or shop-floor level. Visionary champions who have the organisational clout to implement new innovations use a variety of influence strategies including expression of enthusiasms, persuasive arguments and confidence about the innovation (e.g., Howell \& Higgins 1990; Beath 1991). One of the important benefits for engaging these individuals includes their abilities to raise the organisation's BIM knowledge stock, for instance, by addressing occasional concerns or issues raised by the workforce pertaining to the organisation's BIM agendas and other technical constraints they may encounter.

The technology-savvy individuals are given the necessary trainings so that their understanding can align with, and reflect the values and ambitions that underpin the organisations they represent. These technology-savvy individuals are then empowered as "gatekeepers" to facilitate specific technology advancement by ensuring that knowledge is gradually and consistently disseminated across the local organisational contexts. With their enthusiasm and knowledge of the embedded organisational technologies, they occupy a mediating role within the local contexts by supporting novice technology users through a progressive knowledge build-up into becoming well adept at the new innovative practice. This grassroots support strategy is seen to be quite intuitive but very proactive in response to the emergent technological and organisational transformation and in anticipation of the largely unforeseen consequences at the operational level relating to implementation resistance.

\subsection{HR-Driven Incentivisation and Retention Strategy of the Knowledge Workforce}

Within the activity systems of the case organisations, there were obvious tensions and contradictions arising as a direct consequence of the new BIM technological deployment. The case organisations encountered some two main challenges relating to human resource management as a direct result of BIM deployment, and ultimately, employee retention strategies had to be developed to curtail those challenges. It was noted that: 1. people often do not have the motivation to continue learning for self-improvement once they settle down in employment; and 2. Human Resource (HR) strategies often tend to have "a vague approach to managing people" and rely on some "cocktail of values" for motivating, training and retaining existing staff. Nevertheless, BIM-compliant organizations have to be proactive and be ahead of the learning curve to match-up with the evolving technological infrastructures and the related processes. Some of the existing professional staffs from the operational side across the various hierarchies of the organisations were giving new titles to suite their new BIM mandates. More importantly, the new titles trigger a need for additional training in specific skills such as organization approach to BIM project execution and management, and the use of selected BIM software tools for design, coordination and analysis. Specific trainings are also needed for the nascent construction processes such 
as, clash resolution at the design phase, energy analysis, cost and schedule sequencing, and energy use and flythrough simulations. Organisational support strategy was needed to mandate these wholesale process change and the prerequisite knowledge requirements of the workforce. These expansive learning strategies within the work system went a long way to help resolve the brewing tensions between prior knowledge and the requirements of the changing work situations.

It was reported in CS-Alpha for instance, that BIM professionals were "in high demand", hence, it was becoming common for trained BIM employees to seek greenerpastures elsewhere or to be tempted by better offers by competitive organizations. This concern prompted CS-Alpha to initiate a HR action strategy which ensures that the organization retained a good knowledge stock of its workforce, particularly the well trained and experienced BIM professionals. This is in line with Engestrom's expansive learning theory which suggests that the tensions within the work system activities can be recognised as a driving force for expansive learning; that is, resolving current contradictions by developing new form of activity based on an expanded understanding of the epistemic artefacts. The HR department became more engaged and ensured that rewards and salary packages were highly competitive and commensurate with peoples' BIM competences and performance. Project teams and incentivization schemes were also in-place in CS-Beta, this encouraged project teams to concentrate on achieving project-specific BIM targets. This approach corroborates with the expansive learning theory, which typifies continuous growth or enhancement of knowledge and restructuring of prior knowledge to enable a coping mechanism for a totally different or turbulent organizational situation where prior knowledge may prove to be incompatible with the new organizational tasks (Vosniadou, 1994).

Reich et al. (2012) averred that the work organisation must present an enabling environment in which knowledge is created, shared, and utilized to produce the results desired by the organisation. The finding of this study has also added to the knowledge management theory by showing that knowledge dimensions are sustained in BIMcompliant organizations, only if there is a comprehensive and a well formalised employee retention strategy to help maintain a good balance of the knowledge stock. The knowledge stock is enhanced within the case organizations by managing individual progression through different managerial ranks, and by sustaining employee retention through HR-driven formal incentivisation strategies such as performance-based rewards and competitive salary structures.

\subsection{Engagement with External BIM experts and Technology Vendors for Technical Support}

There is recognition in the literature of the myriad institutional, managerial and technological strands of boundary practices that intertwine to influence project outcomes (Whyte \& Sexton 2011). This study has demonstrated that closer collaborative efforts from various knowledge boundaries are needed in order to leverage the organizational benefits rooted in technological innovations. Indeed, all the case organizations solicited the technical expertise of external BIM consultants and support from BIM product vendors - to help draft organisational BIM strategies, to help establish in-house technical BIM team, to provide training, to configure computer systems, and to establish products upgrade and maintenance agreements, among other things.

Notably, construction technological artefacts do not exist in isolation, and the fragmentation of the construction industry manifest in the different functional skills that 
are needed for the delivery of any single project. The reliance on external knowledge sources that complement the organisational efforts suggests that knowledge acquisition to counter the organisational disruptions associated with new technologies cannot be seen as a local phenomenon within specific boundaries, but its dynamism is embodied in expertise operating in multiple perceptive and intellection levels. The recognition of this phenomenon by the respective case organisations consequently leads to more knowledge inflow from the dynamic market into the local contexts.

\section{Conclusions}

The study sought to explore the mechanisms that enable construction organisations to maintain and expand on the required knowledge assets within the workforce to ultimately align with the evolving technological capabilities and organisational ambitions. Expansive learning theory was explored as an essential step to better understand knowledge development and changing processes in the workplace. An enabling workplace environment for expansive learning has been shown to equip the knowledge workforce to tolerate cognitive ambiguities and inherent contradictions of the changing work patterns based on the expanded understanding of the facilitating artefacts (Lehtinen 2012).

The contribution that this study offers is that it illustrates the cognitive synchronisation of the learning approaches within contemporary organisations that align well with the merits and utilities entrenched within their niche technological choices. In particular, the iterative dialogue between the expansive learning theory and the empirical realities of the case organizations present an attractive proposition to conceptualise the contemporary work organization as a learning organization where facilitative learning is deployed to counter any effect or disruptions associated with new innovations. The study has also shown that expansive learning is facilitated by making fitting responses to technological changes within organisations. These responses encompass, inter alia: forming alliances with external consultants, educational institutions and technology vendors; nurturing and developing technology-savvy BIM champions to act as gate keepers in driving the implementation process; HR-driven incentivisation and staff retention schemes such as performance-based rewards and competitive remunerations commensurate with experience; and, skills sharing and knowledge transfers through hands-on learning-by-doing support system for novice operatives who find it difficult to integrate BIM innovations into their work processes.

The results from this study should provide both construction practitioners and academics with insights on how to better understand and prepare the next generation workforce with the requisite knowledge in order to cope with the ever evolving technological and organizational transformation within the AEC sector. The limitation of this study is that, it is restricted to a small-size data sample. The empirical data was drawn from three very specific case organisations therefore the findings could lack statistical generalisability and applicability to a wider context. Hence, it is acknowledged that future comparative studies using a much larger quantitative data sample to expatiate on, or affirm the, findings presented here would be an interesting further step.

\section{References}

Anthony, G., Hunter, R., \& Thompson, Z. (2014). Expansive learning: Lessons from one teacher's learning journey. ZDM, 46(2), 279-291. 
Anumba, C.J. Baugh, C. \& Khalfan, M.M. (2002). Organisational structures to support concurrent engineering in construction. Industrial Management \& Data Systems, 102(5), 260-270.

Beath, C.M. (1991). Supporting the information technology champion. MIS quarterly, 355-372.

Becerik-Gerber, B., Gerber, D. J. \& Ku, K. (2011) The Pace of Technological Innovation in Architecture, EEngineering, and Construction Education: Integrating Recent Trends into the Curricula, Journal of Information Technology in Construction, 16, 411-432.

Bogdan, R. \& Biklen, S. K. (1997). Qualitative research for education, Allyn \& Bacon.

Bowen, G. A. (2009). Document analysis as a qualitative research method. Qualitative research journal, 9(2), 27-40.

Butterfield, L.D., Borgen, W.A., Amundson, N.E. \& Maglio, S.T. (2005). Fifty years of the critical incident techniques: 1954-2004 and beyond. Qualitative Research, 5(4), 475-497

Denis, D., Lortie, M., St-Vincent, M., Gonella, M., Plamondon, A., Delisle, A., Tardif, J. (2013) "Participatory training in manual handling - Theoretical foundations and proposed approach. Montréal: IRSST, Report R-784.

Dubois, A., \& Gadde, L. E. (2002). Systematic combining: an abductive approach to case research. Journal of business research, 55(7), 553-560.

Eastman, C., Teicholz, P., Sacks, R., \& Liston, K. (2011) BIM handbook: A guide to building information modelling for owners, managers, designers, engineers and contractors. Wiley

Engeström, Y. (1994) Training for Change: New Approach to Instruction and Learning in Working Life, International Labour Office, Business and Economics, Geneva.

Engeström, Y. (2001) Expansive Learning at Work: Toward an Activity Theoretical Reconceptualization, Journal of Education and Work, 14(1), 133-156.

Goddard, W. \& Melville, S. (2004) Research Methodology: An Introduction, 2nd edition, Blackwell Publishing

Goering, P.N. \& Streiner, D.L. (2013). Reconcilable differences: The marriage of qualitative and quantitative methods. A Guide for the Statistically Perplexed: Selected Readings for Clinical Researchers, 41, 225.

Hartmann, T., Van Meerveld, H., Vossebeld, N. \& Adriaanse, A. (2012). Aligning building information model tools and construction management methods. Automation in Construction, 22, 605-613.

Hosseini, R., Chileshe, N., Zou, J. \& Baroudi, B. (2013). Approaches of implementing ICT technologies within the construction industry. Australasian Journal of Construction Economics and Building, 1(2), 1-12.

Howell, J. M., \& Higgins, C. A. (1990). Champions of technological innovation Administrative science quarterly, 317-341.

Kaplan, S. \& Orlikowski, W. J. (2013) Temporal Work in Strategy Making, Organization Science, 24(4), 965-995.

Kinnane, O. \& West, R. (2013) BIM Education for Engineers via Self-Directed, Creative Design, International Journal of 3-D Information Modeling (IJ3DIM), 2(4), 65-76.

Lee, N. \& Hollar, D. A. (2013) Probing BIM Education in Construction Engineering and Management Programs Using Industry Perceptions, In 49th ASC Annual Int. Conf. Proc., California Polytechnic State Univ., San Luis Obispo, CA.

Lehtinen, E. (2012) Learning of Complex Competences: On the Need to Coordinate Multiple Theoretical Perspectives, In: A. Koskensalo, J. Smeds, A. Huguet \& R. de Cillia (Eds.), Language: Competencies, Contact, Change 13-27, Berlin: LIT Verlag.

Linderoth, H.C. (2010). Understanding adoption and use of BIM as the creation of actor networks. Automation in Construction, 19(1), 66-72.

Macdonald, J. A. (2012) A Framework for Collaborative BIM Education Across the AEC Disciplines, In: 37th Annual Conference of Australasian University Building Educators Association (AUBEA), 4-6 July, Sydney, Australia.

Milligan, C., Fontana, R. P., Littlejohn, A., \& Margaryan, A. (2015). Self-regulated learning behaviour in the finance industry. Journal of Workplace Learning, 27(5), 387-402. 
Ortiz, O., Castells, F., Sonnemann, G., 2009. Sustainability in the construction industry: a review of recent developments based on LCA. Construction and Building Materials 23, $28-39$.

Raidén, A.B., Dainty, A.R. \& Neale, R.H. (2006). Balancing employee needs, project requirements and organisational priorities in team deployment. Construction Management and Economics, 24(8), 883-895.

Reich, B. H., Gemino, A. \& Sauer, C. (2012) Knowledge Management and Project-Based Knowledge in IT Projects: A Model and Preliminary EmpiricalResults, International Journal of Project Management, 30(6), 663-674.

Research Methods, Series 5.

Sackey, E. (2014) A Sociotechnical Systems Analysis of Building Information Modelling (STSaBIM) Implementation in Construction Organisations, A Doctoral Thesis submitted to Loughborough University

Sackey, E., Tuuli, M. \& Dainty, A. (2014). Sociotechnical systems approach to BIM implementation in a multidisciplinary construction context." Journal of Management in Engineering 31, 1: A4014005.

Steel, J., Drogemuller, R., \& Toth, B. (2012). Model interoperability in building information modelling. Software and Systems Modeling, 11(1), 99-109.

Strauss, A., \& Corbin, J. (1998). Basics of qualitative research. Thousands Oaks.

Underwood, J. \& Ayoade, O. (2015) Current Position and Associated Challenges of BIM Education in UK Higher Education, The High Education Academy, York.

Vosniadou, S. (1994). Capturing and modeling the process of conceptual change. Learning and instruction, 4(1), 45-69.

Whyte, J., \& Sexton, M. (2011). Motivations for innovation in the built environment: new directions for research. Building Research \& Information, 39(5), 473-482.

Yeyinmen, K. C. (2016). Uses of Complex Thinking in Higher Education Adaptive Leadership Practice: A Multiple-Case Study. A Doctoral Thesis submitted to Harvard University.

Yin, R.K. (2003). Case study research: Design and methods. Sage Publications.

Zeichner, K., Payne, K. A., \& Brayko, K. (2015). Democratizing teacher education. Journal of Teacher Education, 66(2), 122-135. 